\title{
Urticaria and Angioedema due to Suspected Induction by Systemic Steroid Drugs
}

\author{
Rezky Darmawan Hatta*, Kristo A. Nababan** \\ * Resident doctor of Dermatology and Venereology, Medical Faculty, Universitas Sumatera Utara, General \\ Hospital Haji Adam Malik, Medan, Indonesia \\ ** Department of Dermatology and Venereology, Medical Faculty, Universitas Sumatera Utara, General \\ Hospital Haji Adam Malik, Medan, Indonesia \\ DOI: 10.29322/IJSRP.11.09.2021.p11714 \\ http://dx.doi.org/10.29322/IJSRP.11.09.2021.p11714
}

\begin{abstract}
Corticosteroids are commonly used in the medical specialty of dermatology because of their antiinflammatory and immunosuppressive effects. Skin hypersensitivity reactions have also been reported with systemically administered corticosteroids. Most of these skin reactions are widespread at presentation, including generalized dermatitis and urticarial reactions. We presented a case of a 25 -year-old woman with shortness of breath accompanied by complaints of red bumps on the neck, trunk, back, stomach, hands and feet since 1 day ago. On examination of the dermatological status, it was found in the anterior thoracic region, posterior thoracic region, abdominal region, superior extremity region, and inferior extremity region. There is urticarial fluorescence, multiple, confluent and generalized. IgE examination showed an increase of 6 times the normal level. Therapy includes oral administration of methylprednisolone, antihistamines, and topical corticosteroids result in good outcome.
\end{abstract}

Index Terms- Hypersensitivity, corticosteroid, urticaria, angioedema

\section{INTRODUCTION}

Corticosteroids are commonly used in the medical specialty of dermatology because of their anti-inflammatory and immunosuppressive effects. ${ }^{1,2}$ Skin hypersensitivity reactions have also been reported with systemically administered corticosteroids, although they are much less common, especially in view of their widespread use worldwide. ${ }^{3}$ Most of these skin reactions are widespread at presentation, including generalized dermatitis and urticarial reactions. Patch testing appears to be successful as the primary tool for diagnosing allergy to orally administered corticosteroids. ${ }^{4-8}$

Urticaria is a disease characterized by localized superficial skin edema of varying size, often surrounded by an erythematous halo accompanied by itching or burning. ${ }^{9}$ Angioedema is an urticaria that occurs in the lower dermis or subcutis layer, often affecting the face and mucous membranes such as the lips, larynx and genitalia. In angioedema pain is more dominant than itching and the rash disappears slowly within 72 hours. ${ }^{10}$

Most cases of urticaria are self-limited and of short duration. However, when urticaria becomes chronic, it will be a problem for the patient or the treating doctor. ${ }^{11}$ Although the pathogenesis and several suspected causes have been found, it turns out that the treatment given sometimes does not give the expected results. ${ }^{12}$ The main management of urticaria includes the following steps: general steps to prevent or avoid trigger factors and pharmacotherapy. The management is stratified into first-line therapy, second-line therapy, and third-line therapy. ${ }^{13}$

\section{CASE REPORT}

A 25-year-old woman came to the Polyclinic Dermatovenereology of Adam Malik Hospital Medan with complaints of red bumps on the neck, body, back, stomach, hands and feet since 1 day before admission to the hospital. Complaints accompanied by itching all over the body. Three days earlier the patient complained of a itchy bump on his hand, the patient scratched it and the bump grew as big as a coin. Then, the patient went to the primary health care and was given dexamethasone and ointment for which no information was given. A day later, itchy red bumps appeared on the chest and back. Red bumps are increasingly spreading to the stomach, hands, and feet accompanied by shortness of breath. After that the patient was immediately brought to the ER and given dexamethasone injection. The patient admitted that after being given the injection drug, the complaints of shortness were getting worse, the body felt weak, and felt dizzy. 
On examination of the dermatological status, it was found in the anterior thoracic region, posterior thoracic region, abdominal region, superior extremity region, and inferior extremity region there is urticarial fluorescence, multiple, some confluent and generalized. IgE examination showed an increase of 6 times the normal level.
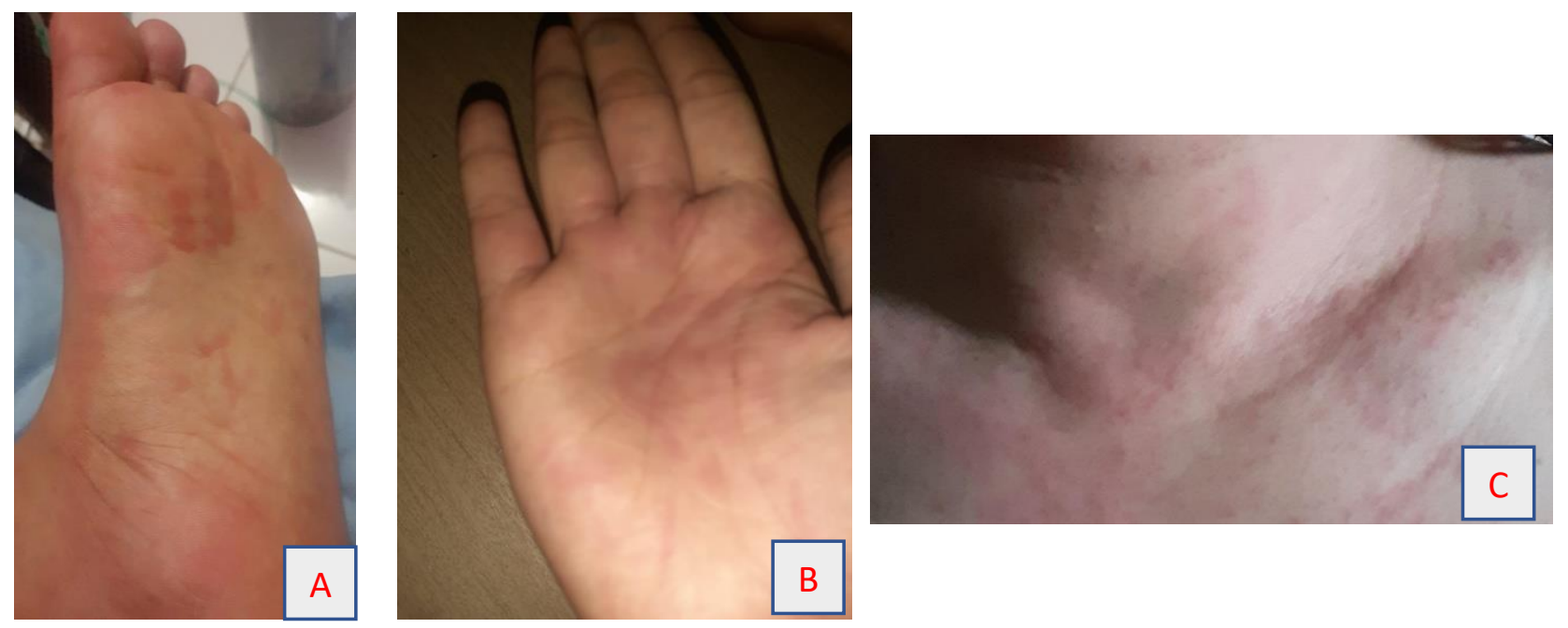

Figure 1. Multiple urticaria in regions A). soles of feet, B). palms, C). neck and chest

General management of the patient includes identifying and discontinuing the causative drug. Specific management includes oral administration of corticosteroid methylprednisolone $4 \mathrm{mg}$ twice a day, antihistamine cetrizine 10mg once a day, topical administration of corticosteroid desoxymethasone cream twice a day.

The first follow-up, the patient came for control 3 days after treatment, it was found that there were no complaints of shortness of breath, no bumps, and no itching. The patient is given the oral antihistamine cetirizine 10 $\mathrm{mg}$ if the itching is still there.
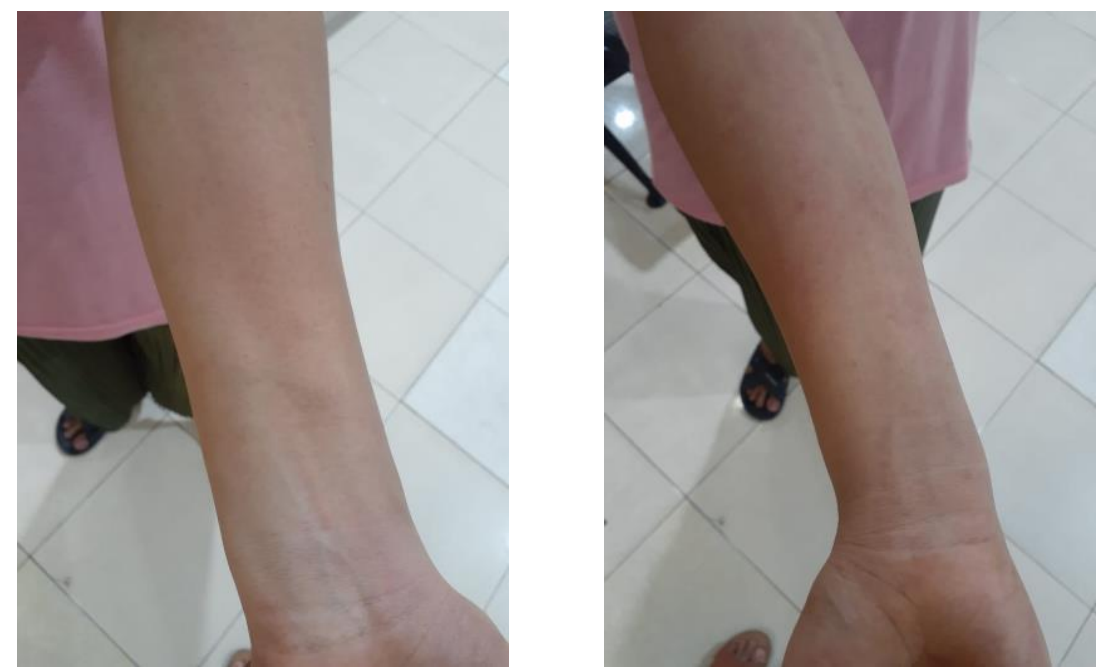

Figure 2. The lesion was repaired, no redness and urticaria were found.

\section{DISCUSSION}

A 25-year-old woman came to the clinic complaining of red bumps on her neck, trunk, back, stomach, hands and feet after being given dexamethasone.The patient was differentially diagnosed with hypersensitivity reactions to steroids and adverse drug reactions. An adverse drug reaction is an unwanted or unwanted effect produced by a drug and that occurs at the appropriate dose. These reactions are predictable and dose-dependent, occurring in normal individuals 
(eg, drug toxicity), or unpredictable and dose-independent, being seen more frequently in genetically susceptible subpopulations. ${ }^{14}$

Patients with hypersensitivity reactions to steroids may present with a variety of clinical signs and symptoms ranging from urticaria $a^{15-17}$ to sudden cardiovascular collapse and death. ${ }^{18-20}$ Some of the more frequently reported events include pruritic rash, ${ }^{21-22}$ bronchospasm ${ }^{15,21}$ and hypotension..$^{21-24}$

On routine blood laboratory examination, no signs of abnormality were found, but on examination the patient's IgE increased by $626.7 \mathrm{IU} / \mathrm{ml}$. Total $\mathrm{IgE}$ counts were considered in the initial studies as the simplest way to identify allergic subjects. For other allergens, the gold standard test for steroid hypersensitivity is a challenge with the suspected agent (ideally double-blinded and placebo-controlled). ${ }^{25}$ Unfortunately, little data exists in the medical literature on provocative testing, particularly for steroid-induced hypersensitivity. Several investigators have conducted IV and oral trials in their patients in controlled settings and found them to be reliable. ${ }^{26-27}$ However, caution is advised as such challenges can trigger a potentially fatal anaphylactic reaction, and subsequently, possibly it is not necessary for clinical purposes.

The patient was given oral corticosteroid methylprednisolone $4 \mathrm{mg}$ twice a day, antihistamine cetrizin 10mg once a day, topical corticosteroid desoxymethasone cream twice a day. Once a patient is suspected of having a steroidinduced hypersensitivity reaction, the suspected agent should be discontinued immediately and not repeated at a later date without testing. Although there is some hesitation when recommending a particular drug, it is prudent to recommend that patients avoid all corticosteroids from the group to which they are sensitized according to the current classification, which serves as a guideline. Since patients reported in the literature often have allergic responses to more than one steroid preparation, ${ }^{17}$ skin tests on various steroids, with and without their diluents and preservatives, should be performed to determine which component of the commercial preparation is responsible for the allergic reaction, and also to determine which component of the commercial preparation is responsible for the allergic reaction. which steroid preparations, if any, are suitable for future use.

\section{CONCLUTION}

Steroid-induced hypersensitivity is a heterogeneous entity. Although very rare, it may be under-recognized because the signs and symptoms overlap with those caused by the disease used to treat steroids. Clinical manifestations of steroid hypersensitivity range from relatively minor reactions such as urticaria to more life-threatening ones, such as bronchospasm and anaphylaxis. Health care professionals need to be aware that steroid hypersensitivity does exist. More detailed investigations are needed in patients with steroid-induced hypersensitivity to clarify issues related to the reaction mechanism.

\section{DISCLOSURE}

The authors report no conflicts of interest in this work.

\section{REFERENCE}

[1] Dooms-Goossens A, Morren M. Results of routine patch testing with corticosteroid series in 2073 patients. Contact Dermatitis. 1992;26:182-91.

[2] Matura M, Goossens A. Contact allergy to corticosteroids. Allergy. 2000;55:698-704.

[3] Scheuer E, Warshaw E. Allergy to corticosteroids: update and review of epidemiology, clinical characteristics, and structural crossreactivity. Am J Contact Derm. 2003;14:179-187.

[4] Von Maur K, Rockin RE, Stevens MB. Corticosteroid allergy in patient with systemic lupus erythematosus. Hopkins Med J. 1974;134:356-64.

[5] Quirce S, Alvarez MJ, Olaguibel JM. Systemic contact dermatitis from oral prednisone. Contact Dermatitis. 1994:30:53-4.

[6] Nucera E, Buonomo A, Pollastrini E, De Pasquale T, Del Ninno M, Roncallo C, et al. A case of cutaneous delayedtype allergy to oral dexamethasone and to betamethasone. Dermatology. 2002;204:248-50.

[7] Brambilla L, Beonschi V, Chiappino G, Fossati S, Pigatto PD. Allergic reactions to topical desoxymethasone and oral triamcinolone. Contact Dermatitis. 1989;21:272-4.

[8] Stingeni L, Caraffini S, Assalve D, Lapomarda V, Lisi P. Erythema-multiforme-like contact dermatitis from budesonide. Contact Dermatitis. 1996;34:154

[9] Zuberbier T. Urticaria: Current opinions about etiology, diagnosis and therapy. Acta Derm Venereol. 2007 : 87 : 196-205.

[10] Zuberbier T. Urticaria. Allergy. $2003: 58: 1224-1234$.

[11] Djuanda, A. (2008). Ilmu Penyakit Kulit dan Kelamin. Jakarta: Fakultas Kedokteran Universitas Indonesia.

[12] Poonawalla, T., Kelly, B. (2009). Urticaria - a review. Am J Clin Dermatol; 10(1): 9-21.

[13] Sheikh, J., Najib, U. (2009). Urticaria. Emedicine, Artikel, dari http://emedicine.medscape.com/article/137362-print

[14] DeSwarte RD. Drug allergy-problems and strategies. J Allergy Clin Immunol 1984;74:209 -224.

[15] Mendelson LM, Meltzer EO, Hamburger RN. Anaphylaxis-like reactions to corticosteroid therapy. J Allergy Clin Immunol 1974:54:125-131.

[16] Clee MD, Ferguson J, Browning MC, et al. Glucocorticoid hypersensitivity in an asthmatic patient: presentation and treatment. Thorax 1985;40:477-478. 
[17] von Maur K, Rocklin RE, Stevens MB. Corticosteroid allergy in a patient with systemic lupus erythematosus. Johns Hopkins Med J 1974;134:356-364.

[18] Thompson J, Chalmers D, Wood R, et al. Sudden death following high-dose intravenous methylprednisolone. Transplantation $1983 ; 36: 594-596$

[19] McDougal BA, Whittier FC, Cross DE. Sudden death after bolus steroid therapy for acute rejection. Transplant Proc 1976; 8:493-496

[20] al Mahdy H, Hall M. Anaphylaxis and hydrocortisone. Ann Intern Med 1988;108:487-488.

[21] Hayhurst M, Braude A, Benatar SR. Anaphylactic-like reaction to hydrocortisone. S Afr Med J 1978;53:259 -260

[22] Rao K, Anderson R, O’Brien TJ. Successful renal transplantation in a patient with anaphylactic reaction to Solu-Medrol (methylprednisolone sodium succinate). Am J Med 1982;72:161-163.

[23] Rodger RS. Anaphylaxis following treatment with a corticosteroid report of one case. Clin Allergy 1983;13:499 -500.

[24] Freedman MD, Schocket AL, Chapel N, Gerber JG. Anaphylaxis after intravenous methylprednisolone administration. JAMA 1981;245:607-608.

[25] Burks AW, Sampson HA. Diagnostic approaches to the patient with suspected food allergies. J Pediatr 1992;121:S64 -S71.

[26] Chan CS, Brown IG, Oliver WA, Zimmerman PV. Hydrocortisone- induced anaphylaxis. Med J Aust 1984;141:444-446.

[27] Becq H, Dequeker J. Hypersensitivity reaction to pulse dose of methylprednisolone (Solumedrol). Acta Clin Belg 1983;38: 262-264

\section{AUTHORS}

First Author - dr. Rezky Darmawan Hatta, Resident doctor of Dermatology and Venereology, Medical Faculty, Universitas Sumatera Utara, General Hospital Haji Adam Malik, Medan, Indonesia, rezkydeha@gmail.com

Second Author - dr. Kristo A. Nababan Sp.KK(K), M.Ked(DV), FAADV, FINSDV, Department of Dermatology and Venereology, Medical Faculty, Universitas Sumatera Utara, General Hospital Haji Adam Malik, Medan, Indonesia.

Correspondence Author - dr. Rezky Darmawan Hatta, rezkydeha@gmail.com, +6282153766786 